\title{
Irregular Breathing in Mice following Genetic Ablation of V2a Neurons
}

\author{
Steven A. Crone, ${ }^{1 \star}$ Jean-Charles Viemari, ${ }^{4 \star}$ Steven Droho, ${ }^{1,2}$ Ana Mrejeru, ${ }^{3}$ Jan-Marino Ramirez, ${ }^{3,5}$ and Kamal Sharma ${ }^{1,2,3}$ \\ ${ }^{1}$ Department of Neurobiology, ${ }^{2}$ Committee on Developmental Biology, and ${ }^{3}$ Committee on Neurobiology, University of Chicago, Chicago, Illinois 60637, \\ ${ }^{4}$ Institut de Neurosciences de la Timone, Laboratoire P3M, UMR 7289-CNRS-Aix Marseille University, 13385 Marseille Cedex 05, France, and ${ }^{5}$ Center for \\ Integrative Brain Research, Seattle Children's Research Institute, Department of Neurological Surgery, University of Washington, Seattle, Washington \\ 98101
}

Neural networks called central pattern generators (CPGs) generate repetitive motor behaviors such as locomotion and breathing. Glutamatergic neurons are required for the generation and inhibitory neurons for the patterning of the motor activity associated with repetitive motor behaviors. In the mouse, glutamatergic V2a neurons coordinate the activity of left and right leg CPGs in the spinal cord enabling mice to generate an alternating gait. Here, we investigate the role of V2a neurons in the neural control of breathing, an essential repetitive motor behavior. We find that, following the ablation of V2a neurons, newborn mice breathe at a lower frequency. Recordings of respiratory activity in brainstem-spinal cord and respiratory slice preparations demonstrate that mice lacking V2a neurons are deficient in central respiratory rhythm generation. The absence of $\mathrm{V} 2 \mathrm{a}$ neurons in the respiratory slice preparation can be compensated for by bath application of neurochemicals known to accelerate the breathing rhythm. In this slice preparation, V2a neurons exhibit a tonic firing pattern. The existence of direct connections between V2a neurons in the medial reticular formation and neurons of the preBötzinger complex indicates that V2a neurons play a direct role in the function of the respiratory CPG in newborn mice. Thus, neurons of the embryonic V2a lineage appear to have been recruited to neural networks that control breathing and locomotion, two prominent CPG-driven, repetitive motor behaviors.

\section{Introduction}

Neurons of the ventral respiratory column (VRC) that includes the pre-Bötzinger complex (pre-BötC) and the parafacial respiratory group or retrotrapezoid nucleus (pFRG/RTN) generate the respiratory rhythm (Onimaru and Homma, 2003; Janczewski and Feldman, 2006; Alheid and McCrimmon, 2008). Many targeted mutations that affect the development of these and other neurons of the hindbrain affect breathing and can be classified into three categories. The first category includes genes that regulate rhombomeric identity in the developing hindbrain. Mutations in hoxal and krox20 genes affect the development of the pFRG, and the phenotype includes slower breathing and more frequent apneas (del Toro et al., 2001; Borday et al., 2005; Chatonnet et al., 2007; Thoby-Brisson et al., 2009). Mutations in hoxa2 do not affect pFRG development; instead, there is an expansion of respiration-related neurons in the locus ceruleus, pe-

Received Jan. 30, 2012; revised April 13, 2012; accepted April 18, 2012.

Author contributions: S.A.C., J.-C.V., J.-M.R., and K.S. designed research; S.A.C., J.-C.V., S.D., A.M., and K.S. performed research; S.A.C., J.-C.V., S.D., A.M., and K.S. analyzed data; S.A.C., J.-C.V., J.-M.R., and K.S. wrote the paper.

This work was supported by grants from the Paralyzed Veterans Association and Muscular Dystrophy Association (K.S.) and by NIH Grants HL/NS60120, HL107084-01, and HL090554 (J.M.R.). This study was conducted as part of an ongoing collaboration between the laboratories of K.S. and J.M.R. We thank Drs. Michael Carroll and Alfredo Garcia for many discussions and help with data analysis.

*S.A.C. and J.-C.V. contributed equally to this work.

Correspondence should be addressed to Kamal Sharma, R218, Knapp Research Center, 924, East 57th Street, Chicago, IL 60637. E-mail: ksharma@bsd.uchicago.edu.

DOI:10.1523/JNEUROSCI.0445-12.2012

Copyright $\odot 2012$ the authors $\quad 0270-6474 / 12 / 327895-12 \$ 15.00 / 0$ dunculopontine tegmental nucleus, and Kolliker-Fuse nucleus (Chatonnet et al., 2007). In hoxa $2^{-1-}$ mice, the frequency of breathing and apneas is not affected; instead, there is an increase in the inspiratory amplitude and tidal volume (Chatonnet et al., 2007). The second category includes genes that regulate neuronal cell fate. Neurons expressing Lbx1, Phox $2 b$, and Math 1 are found in many locations in the CNS including the pFRG/RTN (Pagliardini et al., 2008; Amiel et al., 2009; Rose et al., 2009a; ThobyBrisson et al., 2009). Mutations in these genes disrupt breathing, resulting in lower breathing frequency. In none of the mutants in these two categories has the development of V2a neurons been studied. The third category includes genes that define neurotransmitter phenotype. Reduced excitation and excessive GABA-mediated inhibition in Tlx mutant mice produces respiratory dysfunction (Cheng et al., 2004). Mice homozygous for a null mutation in the vglut2 gene fail to breathe (WallénMackenzie et al., 2006). V2a neurons, Math1 neurons, and neurons in the pre-BötC and pFRG/RTN express vglut2 (Lundfald et al., 2006; Al-Mosawie et al., 2007; Crone et al., 2009; Rose et al., 2009a,b). However, the individual contributions of the many types of glutamatergic neurons to respiration are not known.

Three subtypes of glutamatergic neurons, namely, V2a, V3, and HB9 interneurons, play distinct roles in the functioning of the locomotor CPG (Hinckley et al., 2005; Wilson et al., 2005; Al-Mosawie et al., 2007; Lundfald et al., 2007; Crone et al., 2008, 2009; Zhang et al., 2008). Neurons with similar developmental origin as V2a neurons are also generated in the hindbrain. Whether V2a neurons play a role in the neural control of repeti- 
tive motor behaviors generated by CPGs located in the hindbrain has not been investigated. Here, we demonstrate that, in the absence of V2a neurons, newborn mice show irregular breathing. The breathing deficiency following the ablation of V2a neurons is preserved even in the minimal respiratory network contained within the medullary slice preparation. These data demonstrate that medullary V2a neurons are needed to maintain regular breathing in newborn mammals.

\section{Materials and Methods}

Transgenic animals. All animal care was performed in accordance with the University of Chicago Animal Care and Use Committee. Chx10:LNL: DTA mice containing a protamine-Cre transgene (for germline recombination and removal of the LNL translation stop cassette) were bred to C57BL/6 or ICR females to produce Chx10::DTA mice as described by Crone et al. $(2008,2009)$.

Immunohistochemistry. The locations of hindbrain developmental markers were assessed as follows. Neonatal (P0) pups were anesthetized and perfused with $4 \%$ paraformaldehyde, brains and spinal cords were dissected out, postfixed for $2 \mathrm{~h}$ in $4 \%$ paraformaldehyde, and washed overnight in PBS. Tissue was cryoprotected in $30 \%$ sucrose for $2-4 \mathrm{~h}$ and mounted in OCT medium (Tissue-Tek) for cryosectioning. Coronal sections $(14 \mu \mathrm{m}$ ) of medulla were stained with antibodies to Chx10 (guinea pig; 1:10,000) (Thaler et al., 1999), GATA 2/3 (guinea pig; 1:8000), and/or $\mathrm{NK}_{1} \mathrm{R}$ (rabbit; 1:12,000; Sigma-Aldrich) according to methods previously described (Peng et al., 2007). Species-specific secondary antibodies conjugated to Cy3 or FITC (Jackson ImmunoResearch) were used at a concentration of 1:500-1:750. Images were obtained with a Zeiss Axioplan II microscope, a Zeiss Axiocam digital camera, and analyzed with OpenLab 3.1 software (Improvision). The locations of nuclei positive for Chx10 or GATA3 in medulla sections at the level of the nucleus ambiguus (NA) were plotted relative to the midline and the section boundary. E15.5 embryos were decapitated, fixed $2 \mathrm{~h}$ in $4 \%$ paraformaldehyde, cryoprotected, mounted in OCT, and cryostat sectioned (14 $\mu \mathrm{m})$ for immunostaining using antibodies to $\mathrm{NK}_{1} \mathrm{R}$ and Chx10.

Confocal microscopy. P0 medulla coronal sections (14 $\mu \mathrm{m})$ were immunostained with antibodies to cyan fluorescent protein (CFP) (goat; 1:30,000; Novus), vGLUT2 (guinea pig; 1:2000; Millipore Bioscience Research Reagents), $\mathrm{NK}_{1} \mathrm{R}$ and/or choline acetyltransferase (ChAT) using $\mathrm{Cy} 3$, FITC, and Cy5 secondary antibodies. Single optical sections $(<0.5$ $\mu \mathrm{m}$ ) were obtained for each channel using a Zeiss LSM 5 Pascal confocal microscope with 405, 488, and $543 \mathrm{~nm}$ laser modules for double-labeling experiments or Leica SP2 laser scanning confocal microscope with 405, 488,543 , and $633 \mathrm{~nm}$ laser modules for triple-labeling experiments.

Cell counts. Cell counts of Chx10 and GATA3 neurons were made on coronal sections (14 $\mu \mathrm{m}$ thick, every sixth section counted) immunostained overnight with Chx10 or GATA3 antibodies as described and then visualized with biotin-conjugated anti-guinea pig secondary (overnight at $4^{\circ} \mathrm{C}$ ) followed by $\mathrm{ABC}$ amplification (Vector Laboratories), and SigmaFast DAB (brown) color development (Sigma-Aldrich). Only hemisections adjacent to those containing the nucleus ambiguus (as determined by AChE staining) were counted (6-12 per mouse). For acetylcholinesterase (AChE) staining, tissue sections were incubated for $20-24 \mathrm{~h}$ at $37^{\circ} \mathrm{C}$ in a solution containing $650 \mathrm{~mm}$ sodium acetate, $\mathrm{pH} 5.5$, $100 \mathrm{~mm}$ glycine, $20 \mathrm{~mm}$ cupric sulfate, $2 \mathrm{~mm}$ ethopropazine, and $2 \mathrm{mg} / \mathrm{ml}$ acetylthiocholine iodide. Color development was performed by incubating $10 \mathrm{~min}$ in $1.25 \%$ sodium sulfide, $\mathrm{pH} 6.0$, and then stopped by washing six times in water. Slides were dehydrated in graded ethanol concentrations, and then xylenes, and mounted in Permount (Thermo Fisher Scientific).

In situ hybridization. P0 coronal medulla sections ( $20 \mu \mathrm{m}$, dried) were hybridized with mouse $v$ GLUT2 (811 bp cDNA; courtesy of M. Goulding, Salk Institute, La Jolla, CA)-specific digoxigenin-labeled probes (Schaeren-Wiemers and Gerfin-Moser, 1993). Detection was performed using anti-digoxigenin alkaline phosphatase antibody followed by NBTBCIP color reaction (Roche). For dual in situ hybridization and immunohistochemistry, following the blue in situ color reaction, immunohistochemistry was performed using antibodies to Chx10 and a biotin-conjugated secondary antibody, ABC amplification (Vector Laboratories), and SigmaFast DAB (brown) color development (Sigma-Aldrich).

Plethysmography. Whole-body plethysmography was performed on age P0-P28 wild-type and Chx10::DTA mice. Animals were placed in a barometric chamber and equilibrated to the chamber with open air flow for $10 \mathrm{~min}$ (age, P0-P6) or $30 \mathrm{~min}$ (age, P12-P28). Chamber size was adjusted for each age group using Plexiglas inserts or a custom-built chamber ( $\mathrm{P} 0$ pups). The chamber was sealed for a $60 \mathrm{~s}$ recording session, and the pressure difference was measured between the experimental and reference chamber with a differential pressure transducer. Only recording periods in which the animals were immobile were analyzed. At least 3 min of open air flow was allowed between trials. Signals were amplified, digitized, and low-pass filtered $(0.1 \mathrm{~Hz})$. Data were collected and analyzed using pCLAMP 9.0 software (Molecular Devices). For ages P0-P6, the same wild-type and Chx10::DTA animals were recorded on P0, P2, $\mathrm{P} 4$, and $\mathrm{P} 6$.

Brainstem spinal cord preparation. P0 wild-type and Chx10::DTA mice were anesthetized and decerebrated, and the medulla and cervical spinal cord were dissected out and placed ventral side up in a recording chamber superfused with artificial CSF (aCSF) bubbled with 5\% $\mathrm{CO}_{2} / 95 \% \mathrm{O}_{2}$. The rhythmic phrenic burst activity was recorded using a suction electrode on the fourth cervical ventral root as described previously (Viemari et al., 2004).

Medullary respiratory slice preparation. Transverse medulla slice preparations were made from neonatal (P0) wild-type and Chx10::DTA mice. Brainstems were dissected out and placed in ice-cold artificial CSF bubbled with $5 \% \mathrm{CO}_{2} / 95 \% \mathrm{O}_{2}$ and serially sliced at a $20^{\circ}$ angle with a vibratome until disappearance of the parafacial group and appearance of the inferior olive, nucleus ambiguus, and the hypoglossal nucleus. A 600 $\mu \mathrm{m}$ slice containing these landmarks was placed in a recording chamber at $29 \pm 0.5^{\circ} \mathrm{C}$ superfused with oxygenated aCSF containing the following (in mM): $118 \mathrm{NaCl}, 25 \mathrm{NaHCO}_{3}, 3 \mathrm{KCl}, 1 \mathrm{NaH}_{2} \mathrm{PO}_{4}, 1.5 \mathrm{CaCl}_{2}, 1 \mathrm{MgCl}_{2}$, and 30 glucose, $\mathrm{pH} 7.4$, bubbled with $5 \% \mathrm{CO}_{2} / 95 \% \mathrm{O}_{2}$. The potassium concentration was raised from 3 to $8 \mathrm{~mm}$ over $30 \mathrm{~min}$ to initiate and maintain fictive respiratory rhythmic activity. Population activity of the ventral respiratory group (VRG) was recorded using a suction electrode on the surface of the slice. The signals were amplified, filtered (low pass, $1.5 \mathrm{kHz}$; high pass, $250 \mathrm{~Hz}$ ), rectified, and integrated (time constant, $60 \mathrm{~ms}$ ).

Data analysis of C4 and VRG recordings. All physiological recordings were stored on a personal computer using AxoTape (version 2.0; Molecular Devices) and analyzed off-line using customized analysis software written with IGOR Pro (Wavemetrics). We measured C4 and VRG burst frequency, amplitude, and duration. Bursts were automatically detected by the IGOR program as described extensively in our previous study (Lieske et al., 2000; Viemari and Ramirez, 2006). Measured parameter values are reported in the text as mean \pm SD for all C4 and VRG recordings. Burst duration was measured as the width at half-maximum amplitude. To estimate the cycle duration variability, we calculated the coefficient of variability of cycle duration defined as the ratio between the $\mathrm{SD}$ and the mean cycle duration measured during 30-60 successive cycles (Viemari et al., 2004). To further determine whether the pattern of bursts was predictable or random, we calculated approximate entropy (ApEn) values using the algorithm developed by Pincus et al. (1991) for 20 consecutive bursts for each wild-type or mutant slice. As described in detail by Duclos et al. (2008), two input parameters have to be specified for ApEn computations: $m$, the run length (the length of a sequence of contiguous observations), and $r$, the filter (also called the criterion of similarity, a fixed value between 10 and $25 \%$ of SD). In the present study, the run length was $m=1$ (the duration of each interburst interval was compared with the following one), and $r=10 \%$ of SD. Smaller ApEn values reflect a predictable pattern of bursts. Conversely, random data result in higher ApEn values (high irregularity). Poincaré maps were constructed by plotting the period $\left(T_{n}\right)$ versus the subsequent period $\left(T_{n+1}\right)$ between bursts recorded from transverse slices or between inspiratory peaks in plethysmography recordings. Statistical comparisons of coefficient of variation (CV) values were performed using the Mann- 
Whitney rank sum test. All other statistical comparisons were performed using Student's $t$ test.

Pre-BötC retrograde tracing. The pre-BötC was identified by rhythmic bursting activity at the surface of medullary respiratory slices (see above, Medullary respiratory slice preparation). The recording electrode was then filled with fluorescein-dextran and lowered into the slice just below the surface for $1-2 \mathrm{~h}$ to allow uptake and retrograde transport by axons damaged at the site of injection. Slices were fixed in $4 \%$ paraformaldehyde for $2 \mathrm{~h}$, cryoprotected in $30 \%$ sucrose, and mounted in OCT for cryostat sectioning $(14 \mu \mathrm{m})$. Colocalization of Chx10 and fluoresceindextran was determined after immunostaining for Chx10 as described above.

Intracellular recordings. Chx10::CFP mice (age P0) were anesthetized with ether and decapitated. Coronal slices ( $300 \mu \mathrm{m}$ thick) were prepared from the ventral medulla using a Vibratome (Leica VT1000S). Slices were maintained at room temperature in the recording solution until use (1-2 h). Slices were mounted in a chamber on the stage of an upright microscope (Axioskop; Zeiss) and visualized by infrared-differential interference contrast video microscopy through a $40 \times$ water-immersion objective with ORCA-ER camera (Hamamatsu). Fluorescence was visualized using a Lambda DG-4 high-speed filter changer (Sutter Instrument) with CFP excitation at $436 \mathrm{~nm}$ and emission at $480 \mathrm{~nm}$ (Chroma filters). Images were captured using MetaMorph software (Molecular Devices).

Slices were superfused continuously at a rate of $5 \mathrm{ml} / \mathrm{min}$ with oxygenated aCSF. The slice temperature was maintained at $31^{\circ} \mathrm{C}\left( \pm 2^{\circ} \mathrm{C}\right)$. Patch pipettes $(2-6 \mathrm{M} \Omega$ ) were pulled from borosilicate glass (G150F-4; Warner Instruments) and filled with internal solution containing the following (in $\mathrm{mM}$ ): 138 potassium-methane sulfonate, 10 HEPES, 10 EGTA, 4 $\mathrm{Na}_{2} \mathrm{ATP}, 0.3 \mathrm{Na}-\mathrm{GTP}, 2 \mathrm{MgCl}_{2}, 1 \mathrm{CaCl}_{2}$, and $0.1 \%$ rhodamine-dextran (Invitrogen), pH 7.2, 300-315 mOsm. Whole-cell intracellular recordings were made from individual Chx10 neurons using an Axopatch 1D amplifier (Molecular Devices). Data were digitized at $5 \mathrm{kHz}$ and low-pass filtered before acquisition (Bessel characteristic of $5 \mathrm{kHz}$ cutoff frequency). Data are reported as mean \pm SEM. Membrane potential values shown are not corrected for the liquid junction potential of $-8.2 \mathrm{mV}$ and are reported as raw values from the amplifier monitor.

\section{Results}

Early neonatal death in mice lacking V2a neurons

Previously, we generated a Chx10::DTA mouse line to selectively ablate V2a neurons by targeted expression of diphtheria toxin A-chain (DTA) under the control of the endogenous ch $x 10$ gene promoter (Crone et al., 2008, 2009). These mice are generated by mating a $\operatorname{ch} \times 10^{\text {PNP:DTA/+ }}$, prm:cre C57BL/6 sire with wild-type C57BL/ 6 or ICR dams. As reported previously, Chx10::DTA mice born to C57BL/6 dams fail to survive past P0. Born to ICR dams, $60 \%$ of Chx10::DTA mice die within $3 \mathrm{~d}$ after birth and the remaining $40 \%$ that are alive on day 4 survive to adulthood (Crone et al., 2009). To test whether the difference in survival between progenies of C57BL/ 6 and ICR dams is due to the degree of V2a neuron ablation, we performed V2a neuron counts in the medulla. Comparison of Chx10 expression in wild-type and Chx10::DTA mice demonstrates that $>98 \%$ of V2a neurons are ablated in the medulla of Chx10::DTA mice by the age P0 in both C57BL/6 [number of Chx10 neurons \pm SEM: $99.7 \pm 5.3$ wildtype $(n=5) ; 1.2 \pm 0.2$ Chx10::DTA $(n=5) ; p<0.005]$ and ICR genetic backgrounds [number of Chx10 neurons \pm SEM: $111.3 \pm 6.9$ wild-type $(n=3) ; 2.2 \pm 0.3 \mathrm{Chx} 10:: \mathrm{DTA}(n=3) ; p<$ $0.005]$. Furthermore, in both strains there was no significant difference in the number of GATA3-expressing neurons in Chx10::DTA mice compared with wild-type mice [number of GATA3 neurons \pm SEM for C57BL/6: $106.0 \pm 2.6$ wild-type $(n=$ 5), $114.4 \pm 2.6$ Chx10::DTA $(n=5), p>0.05$; number of GATA3 neurons \pm SEM for ICR: $99.9 \pm 7.7$ wild-type $(n=3), 93.8 \pm 7.2$ Chx10::DTA $(n=3), p>0.05]$. The GATA3-expressing V2b

\section{a}

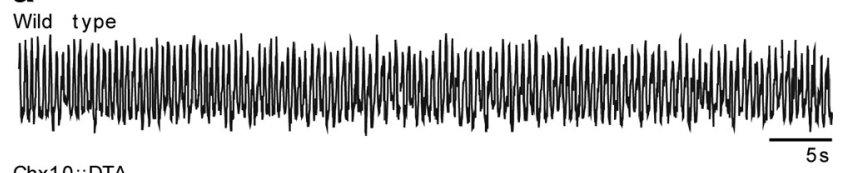

Chx10 :DTA

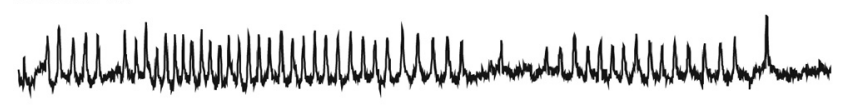

b
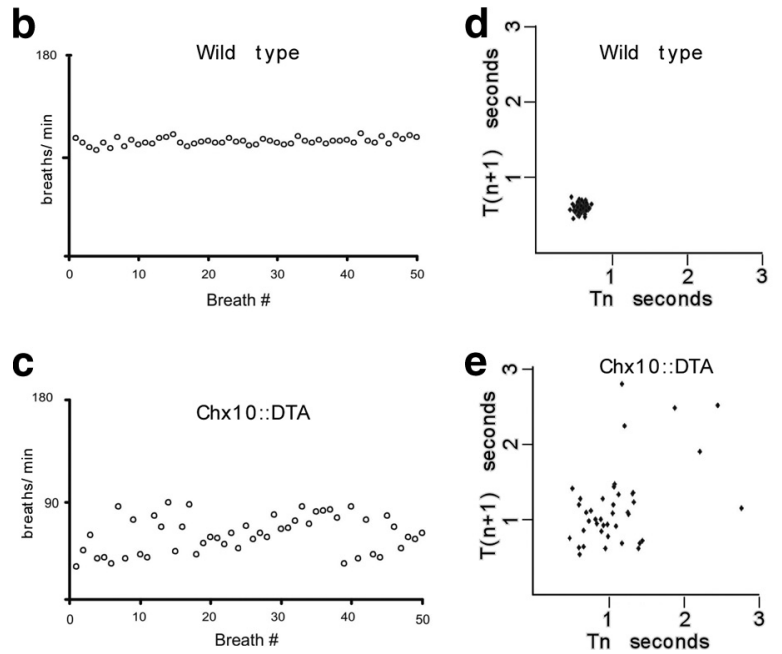

Figure 1. Ablation of V2a neurons in the medulla of Chx10::DTA mice results in slow, irregular breathing. $\boldsymbol{a}$, Whole-body plethysmographs from P0 wild-type (top) and Chx10::DTA (bottom) mice born to C57BL/6 dams show inspiration as upward deflections in the graph. $\boldsymbol{b}, \boldsymbol{c}$, Instantaneous respiratory frequency (breaths/minute) is plotted for 50 consecutive breaths in a P0 wild-type mouse (b) and a Chx10::DTA mouse (c) born to C57BL/6 dams to illustrate the breath to breath consistency of respiratory frequency. $\boldsymbol{d}, \boldsymbol{e}$, Poincare maps of the respiratory period $\left(T_{n}\right)$ in seconds versus the subsequent period $\left(T_{n+1}\right)$ of a P0 wild type $(\boldsymbol{d})$ and a Chx10::DTA (e) mouse as measured by plethysmography.

neurons are generated from the same pool of neural progenitors as V2a neurons. These data demonstrate that the difference in survival of Chx10::DTA mice born to C57BL/6 and ICR dams cannot be explained simply by the efficiency or specificity of V2a neuron ablation.

\section{Breathing deficiency in mice lacking V2a neurons}

Genetic variability plays an important role in breathing. For example, the C57BL/6 mice are more prone to breathing irregularities and apneas compared with mice of other strains (Stettner et al., 2008; Yamauchi et al., 2008). We predicted that neonatal C57BL/6 mice might be less tolerant to experimentally induced breathing irregularities compared with the ICR mice. We tested breathing in P0 Chx10::DTA and their control littermate pups born to C57BL/6 and ICR dams using whole-body plethysmography. In the case of mice born to $\mathrm{C} 57 \mathrm{BL} / 6$ dams, plethysmographic recordings (Fig. 1a) reveal that newborn Chx10::DTA pups inspire less frequently compared with wild-type littermates $(106 \pm 9 \mathrm{cycles} / \mathrm{min}$ vs $45 \pm 7 \mathrm{cycles} / \mathrm{min} ; p=0.008 ; n=7$ wild-type, 7 Chx10::DTA). Newborn Chx10::DTA pups show irregular breathing. The frequency of breathing varies greatly from one breath to the next in Chx10::DTA pups compared with wildtype pups (Fig. 1b,c). Further analysis of the temporal structure of the breathing irregularity in Chx10::DTA mice was done by generating Poincaré maps (Del Negro et al., 2002; Mellen et al., 2003). Poincaré maps are generated by plotting the breathing period $\left(T_{n}\right)$ versus that of the subsequent breath $\left(T_{n+1}\right)$ in a con- 
tinuous series of successive breaths. When the breathing is normal, as in wild-type pups (Fig. 1d), points in a Poincaré map form a tight cluster. In contrast, the Poincaré map of Chx10::DTA pups are disperse (Fig. 1e), indicating that the breathing period fluctuates from breath to breath. Next, we analyzed breathing in P0 Chx10::DTA pups and their control littermates born to ICR dams at various ages from P0 to P28. At P0 and P2, ICR Chx10::DTA mice exhibit a reduced breathing frequency compared with wild type and increased variability in respiratory rate as measured by the coefficient of variation of the frequency (Fig. $2 a, b, g, h$ ). As with pups born to $\mathrm{C} 57 \mathrm{BL} / 6$ dams, breath-to-breath plots of the breathing frequency show that the breathing period of P0 and P2 ICR Chx10::DTA pups varies from breath to breath (Fig. $2 d, e$ ). However, by P4, the frequency of breathing in Chx10::DTA mice is comparable with littermate wild-type control mice of the same genetic background, as is the coefficient of variation and breath-to-breath variation in the frequency (Fig. $2 c, f, g, h$ ). Between P6 and P28, Chx10::DTA mice breathe less frequently compared with wild-type controls (Fig. $2 g$ ). However, the breathing pattern seems to be regular as measured by similar coefficient of variation in Chx10::DTA and wild-type control mice (Fig. 2h). These data demonstrate that the loss of glutamatergic V2a neurons leads to an irregular breathing pattern in neonatal mice of both C57BL/6 and ICR genetic backgrounds. As these mice mature, breathing becomes more regular, but the frequency of breathing remains slower.

\section{Central origin of breathing deficit in Chx10::DTA mice}

To exclude possible afferent influences on respiratory behavior, we isolated the brainstem-spinal cord of P0 Chx10::DTA mice (C57BL/6) and recorded respiratory activity from the C4-root. As with plethysmography recordings, significant differences were observed in C4 burst activity in preparations obtained from P0 Chx10::DTA mice compared with wild-type littermates (Fig. 3ad). The frequency of C4 burst activity was significantly lower $(0.12 \pm 0.02$ vs $0.19 \pm 0.01 \mathrm{~Hz} ; p=0.008 ; n=6$ wild-type, 7 Chx10::DTA), and the variability of the interburst interval significantly higher in Chx10::DTA preparations compared with wildtype littermates $(\mathrm{CV}=0.45 \pm 0.03$ vs $0.30 \pm 0.02 ; p=0.012)$. However, the relative amplitude of individual bursts, measured as the area under an integrated burst, and burst duration were similar in Chx10::DTA and wild-type littermates [burst amplitude: $0.42 \pm 0.12$ vs $0.30 \pm 0.06, p=0.229$; burst duration (in seconds): $0.52 \pm 0.08$ vs $0.40 \pm 0.07, p=0.629]$. These data demonstrate that V2a neurons located in the brainstem and spinal cord play a role in determining the frequency and regularity of respiratory motor neuron activity without affecting the amplitude or duration of each firing episode.
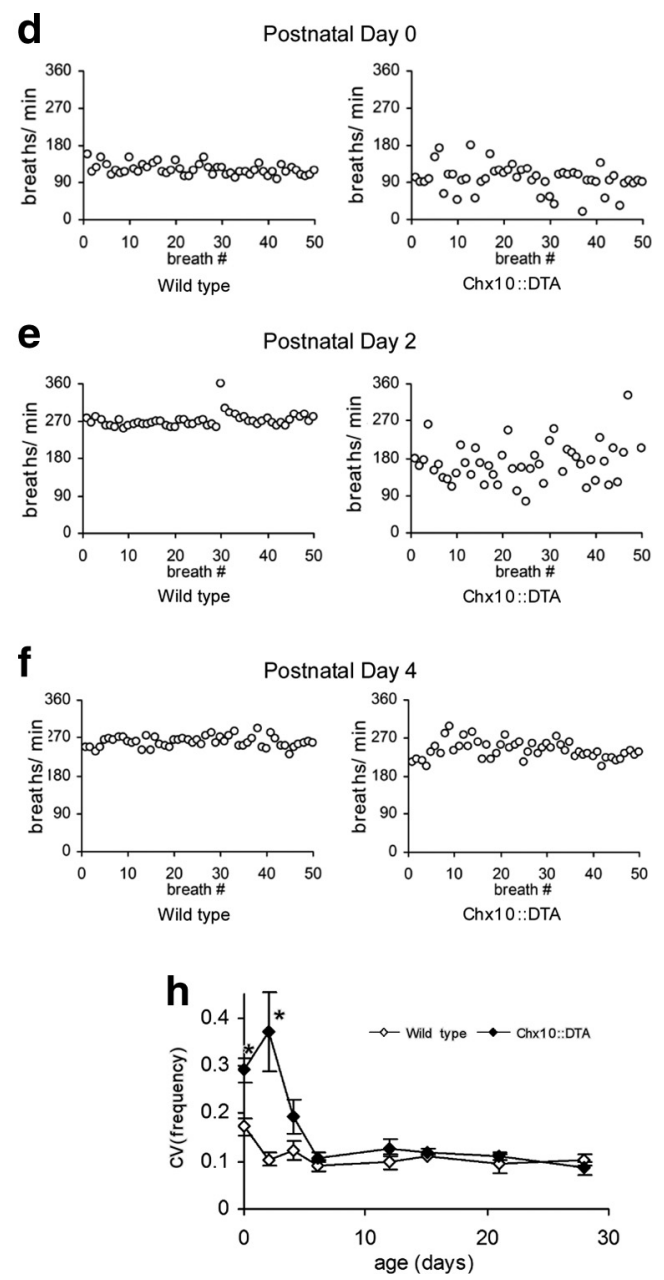

Figure 2. Postnatal changes in breathing regularity by Chx10::DTA mice. $\boldsymbol{a}-\boldsymbol{c}$, Whole-body plethysmography was performed at and Chx10::DTA mice, $\boldsymbol{h}$, The CV of the respiratory frequency as a function of age in P0 -P28 wild-type and Chx10*:DTA mice. Error bars indicate SEM. The asterisk $\left({ }^{*}\right)$ denotes Chx10::DTA versus wild type. $p<0.05$ by Student's $t$ test $(\boldsymbol{g})$ or Mann-Whitney rank sum test $(\boldsymbol{h})$. The number of wild-type and Chx10::DTA animals, respectively, analyzed for each age is P0 $(4,6), \mathrm{P} 2(4,5), \mathrm{P} 4(4$, 5), P6 (4, 5), P12 (4, 3), P15 (3, 3), P21 (5, 5), and P28 (6, 6).

A neural network that can generate rhythmic respiratory output is contained within a transverse slice from the medulla (Smith et al., 1991). Essential to the generation of the inspiratory rhythm in this transverse medullary slice are neurons located in the preBötC (Gray et al., 1999, 2001) of the VRG. First, we asked whether the ablation of V2a neurons affects the development of the preBötC. Many neurons in the pre-BötC and the adjacent nucleus ambiguus express the $\mathrm{NK}_{1} \mathrm{R}$ receptor. The neurons of the preBötC can be identified by the lack of ChAT immunoreactivity, a marker for cholinergic neurons of the nucleus ambiguus. Expression of $\mathrm{NK}_{1} \mathrm{R}$ is indistinguishable in P0 wild-type and Chx10::DTA mice (Fig. $3 e, f$ ). In wild-type mice, $\mathrm{NK}_{1} \mathrm{R}$ expressing neurons of the pre-BötC and nucleus ambiguus are clearly visible by E15.5, and these neurons are located lateral to the V2a neurons (Fig. 3g). At the same developmental stage, nearly all V2a neurons have been ablated in the Chx10::DTA mice; however, the $\mathrm{NK}_{1} \mathrm{R}$-expressing neurons appear normal (Fig. 3h). Next, we compared inspiratory-like activity in transverse medullary slices from P0 Chx10::DTA mice and wild-type littermates. Inspiratory rhythmic burst activity was recorded in 
a Wild type

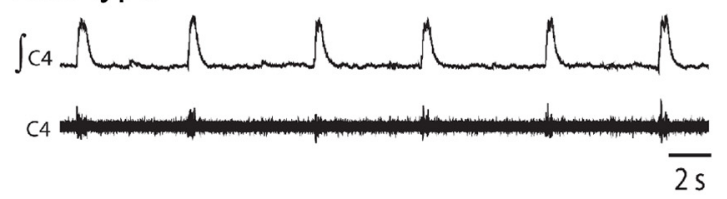

b Chx10::DTA

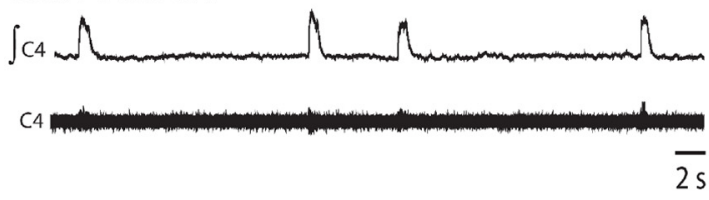

C
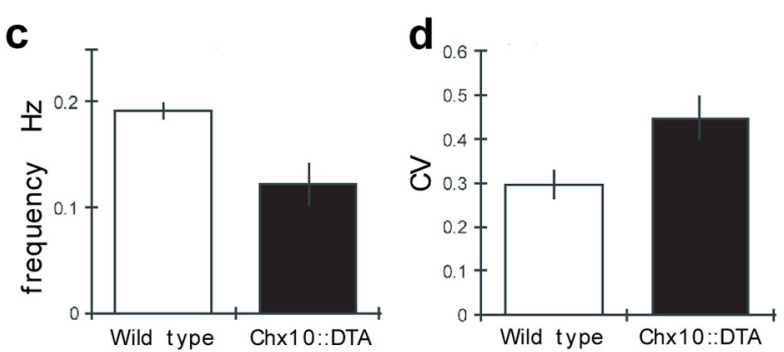

i Wild type

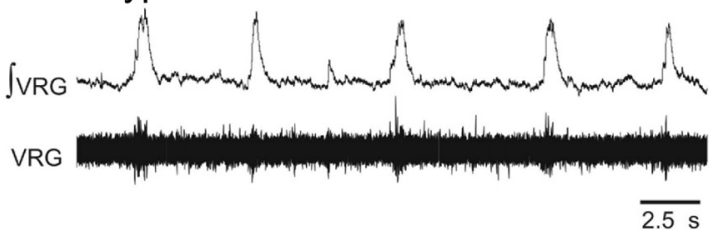

j Chx10::DTA

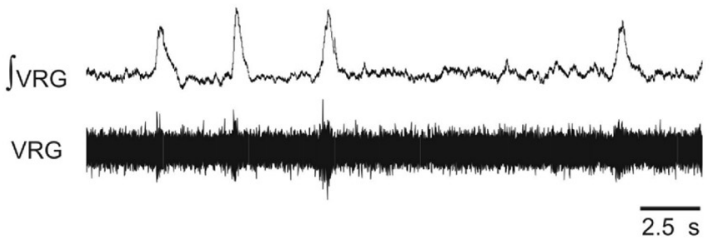

NK1R ChAT
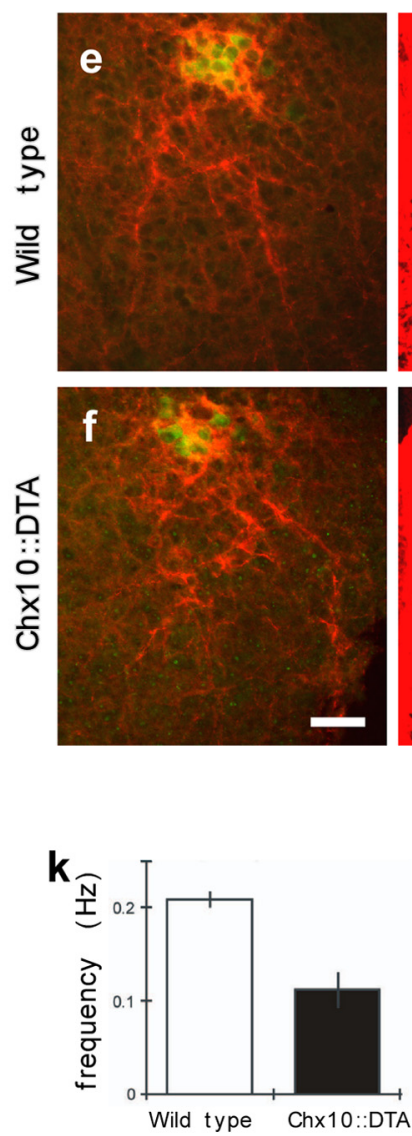

I

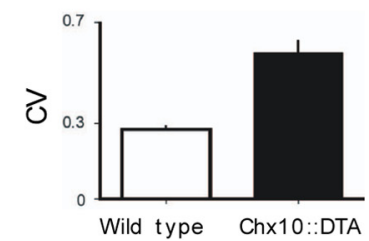

NK1R Chx10
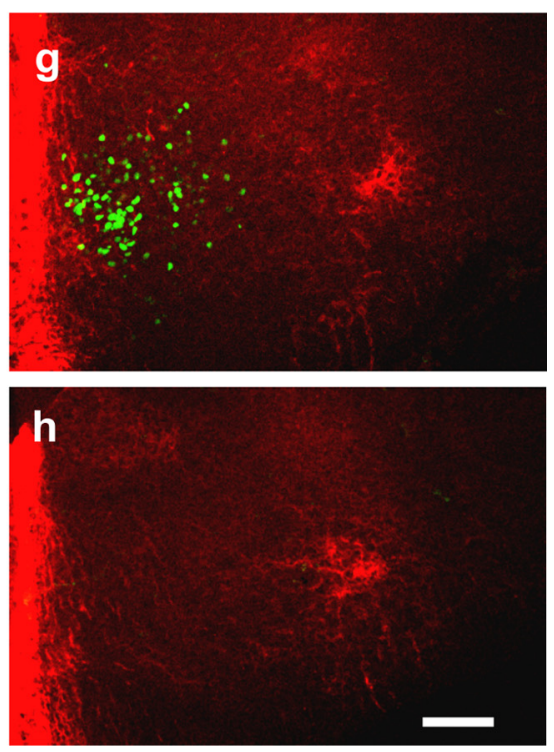

m

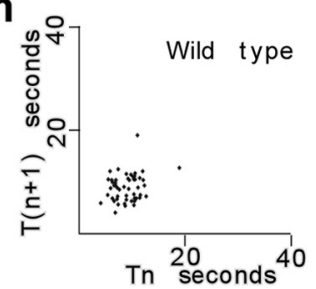

n

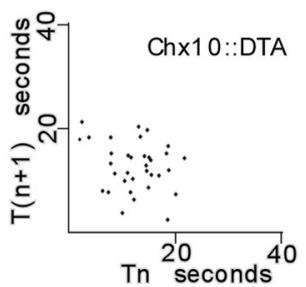

Figure 3. Respiratory rhythm generation is slow and irregular in P0 Chx10::DTA mice. $\boldsymbol{a}-\boldsymbol{d}$, Activity of the C4 ventral root was recorded in brainstem-spinal cord preparations from wild-type (a) and Chx10::DTA (b) mice. Integrated (top trace) and raw (bottom trace) C4 root recordings are shown. The average frequency in hertz (c) of (4-root burst activity is significantly decreased, whereas the variability (coefficient of variation) of the interburst interval $(\boldsymbol{d})$ is increased in Chx10::DTA $(n=7)$ compared with control mice $(n=6)$. $\boldsymbol{e}, \boldsymbol{f}$, Coronal sections of age P0 medulla from wild-type $(\boldsymbol{e})$ and Chx10::DTA ( $\boldsymbol{f}$ ) mice immunostained for NK $\mathrm{R}_{1}$ (red) and ChAT (green). NK $\mathrm{R}_{1}$ marks neurons of the pre-BötC and nucleus ambiguus, whereas ChAT marks only the nucleus ambiguus. $\boldsymbol{g}, \boldsymbol{h}$, At E15.5, the medulla of a Chx10::DTA ( $\boldsymbol{h}$ ) embryo shows a lack of Chx10 neurons (green), but no changes in NK $\mathbf{R}$ (red) staining compared with a wild-type ( $\boldsymbol{g}$ ) embry0. $\boldsymbol{i}, \boldsymbol{j}$, Rectified (top) and raw (bottom) extracellular recordings of rhythmic burst activity in the VRG of medullary slice preparations from P0 wild-type (i) and Chx10::DTA (j) mice. $\boldsymbol{k}$, The average frequency in hertz of VRG burst activity in medullary slices from wild-type $(n=10)$ and Chx10::DTA mice $(n=10)$. Decreased burst frequency in Chx10::DTA mice compared with wild type is accompanied by higher variability in the interburst interval [measured as the coefficient of variation $(I)$ ]. Error bars indicate SEM. $\boldsymbol{m}, \boldsymbol{n}$, Poincaré maps of the period between bursts $\left(T_{n}\right)$ in seconds versus the subsequent period $\left(T_{n+1}\right)$ of VRG burst activity in medullary slices from a P0 wild-type ( $\boldsymbol{m})$ and a Chx10::DTA ( $\boldsymbol{n})$ mouse. Scale bars: $\boldsymbol{e}, \boldsymbol{f}, 50 \mu \mathrm{m} ; \boldsymbol{g}, \boldsymbol{h}, 100 \mu \mathrm{m}$.

the VRG from all slices prepared from Chx10::DTA mice and wild-type littermates under standard conditions (Fig. 3i,j). However, the frequency of burst activity was significantly lower in the Chx10::DTA mice compared with controls $(0.11 \pm 0.01$ vs $0.22 \pm$

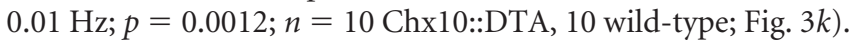
In addition to the lower mean frequency, the coefficient of variation of the interburst interval was significantly higher in slices from Chx10::DTA mice compared with control slices $(0.58 \pm$ 0.04 vs $0.28 \pm 0.01 ; p=0.0012$; Fig. $3 l$ ). Despite significant changes in the frequency and regularity of the rhythm, the burst amplitude and duration of individual bursts were similar in slices from Chx10::DTA and wild-type littermates [burst amplitude: $0.27 \pm 0.04$ vs $0.30 \pm 0.06, p=0.343$; burst duration (in sec- onds): $0.53 \pm 0.04$ vs $0.46 \pm 0.02, p=0.286]$. These data demonstrate that $\mathrm{V} 2 \mathrm{a}$ neurons of the medulla are required to maintain the frequency and regularity of burst activity in the mouse pre-BötC.

We further analyzed the transition between successive inspiratory burst periods using Poincaré maps. We plotted the period between bursts $\left(T_{n}\right)$ versus the subsequent period $\left(T_{n+1}\right)$ for a series of inspiratory bursts recorded from the pre-BötC in slices from P0 Chx10::DTA and wild-type mice. As observed in the case of plethysmography recordings from intact mice (Fig. 1d,e), points in Poincaré maps from wild-type slices form a tight cluster (Fig. $3 m$ ), whereas those from Chx10::DTA slices are scattered (Fig. $3 n$ ). This analysis reveals that the interburst periods ob- 
a

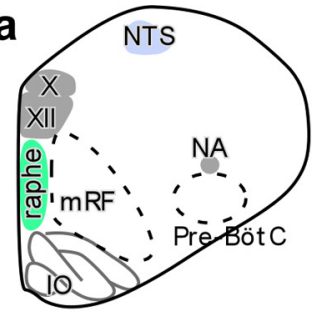

b

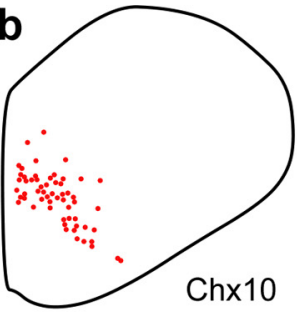

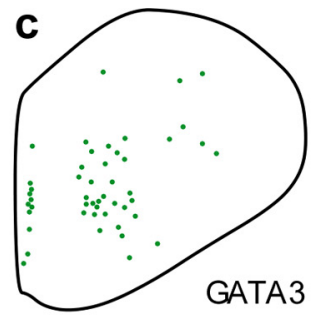

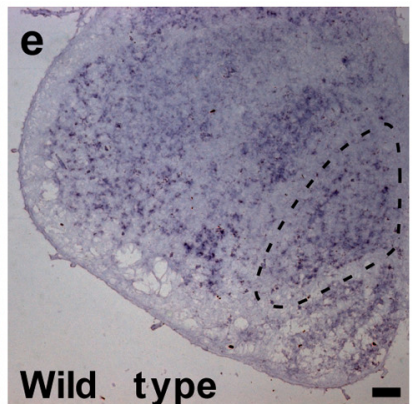

g
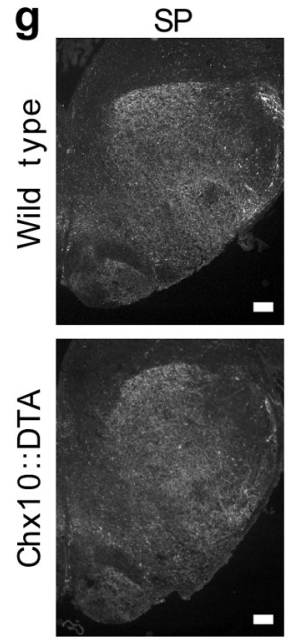

h

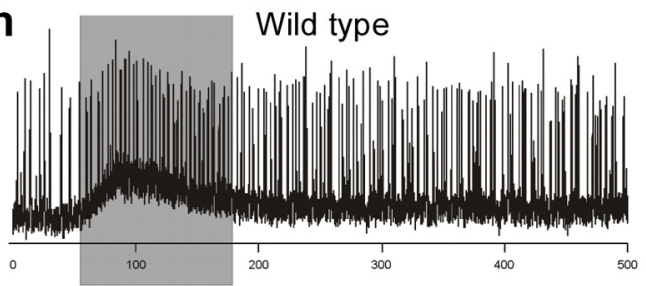

SP $0.75 \mu \mathrm{M}$

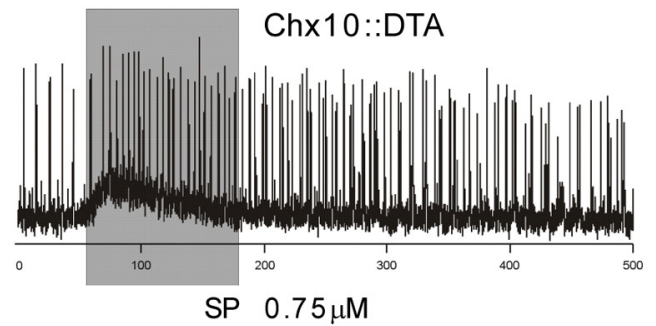

$\mathbf{K}_{0.8}$
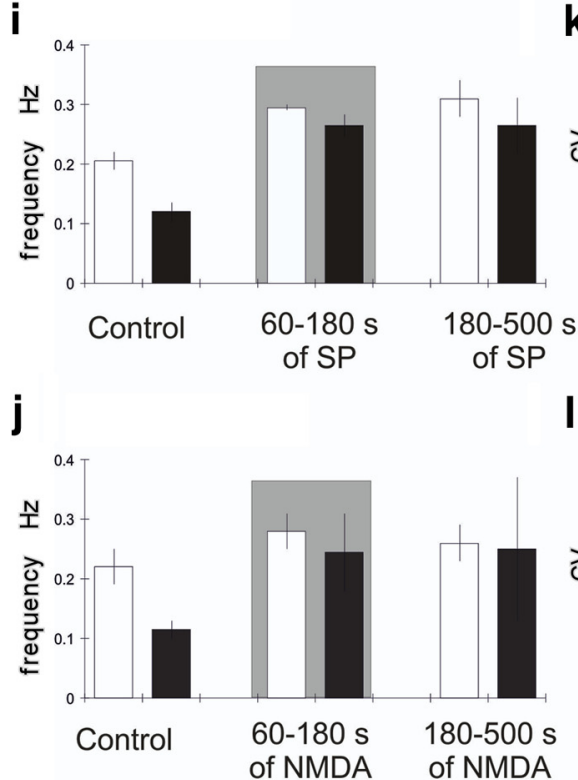

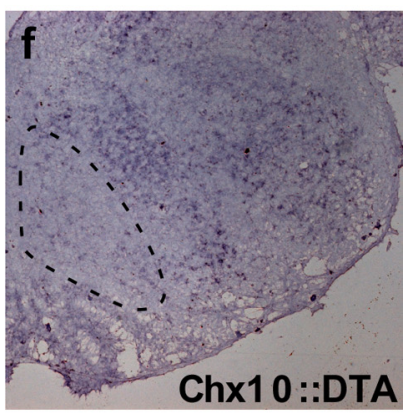

Chx10::DTA

served in recordings from the pre-BötC in Chx10::DTA slices vary widely from breath to breath. The relationship between successive bursts was also analyzed using ApEn, a statistic that detects changes in the regularity of an ordered series of events (Duclos et al., 2008). The ApEn values, unlike the coefficient of variation, are dependent on the order of events rather than just the variance within a data set and measure the predictability of successive points in a data set. The ApEn values were larger (more unpredictable) in the case of Chx10::DTA mice compared with the wild-type littermates (Chx10::DTA: ApEn $=0.26 \pm 0.02, n=5$; wild-type: ApEn $=0.12 \pm 0.03, n=5 ; p=$ $0.016)$. These results demonstrate that the loss of V2a neurons causes a failure in the ability of the pre-BötC neurons to maintain a constant or predictable interburst period between successive bursts of activity.

Neurochemical activation of the respiratory network compensates for the lack of V2a neurons in the medulla In the mouse medulla, V2a neurons are located lateral to serotonin-expressing cells of the raphe (Fig. 4a,b). In comparison, neurons that express the V2b marker

glossal (XII), vagus (X), and nucleus ambiguus (NA) motor nuclei, nucleus of the solitary tract (NTS), raphe, medial reticular formation (mRF), and the pre-BötC. Also shown is the inferior olivary nucleus (10). $\boldsymbol{b}, \boldsymbol{c}$, Drawings of coronal sections from age $\mathrm{P} 0$ mouse medulla showing the location of $\mathrm{Chx} \times(\boldsymbol{b})$ and GATA3 (c) interneurons as determined by immunohistochemistry. Chx10 neurons are located predominantly within the presumed mRF region. $\boldsymbol{d}$, Dual in situ hybridization and immunohistochemistry in the medullary mRF demonstrate that Chx10 neurons (brown nuclei) express vglut2 mRNA (blue cytoplasmic staining). $\boldsymbol{e}, \boldsymbol{f}$, In situ hybridization for vglut2 mRNA at age $\mathrm{P} 0$ shows fewer glutamatergic neurons in Chx10::DTA ( $f$ ) compared with wildtype (e) mice in the mRF (outlined by dashed line), but not in dorsolateral medulla. $\boldsymbol{g}$, The distribution of SP immunoreactivity is similar in the medulla of $\mathrm{PO}$ wild-type (top) and Chx10::DTA mice (bottom). $\boldsymbol{h}$, Rectified traces showing that bath-applied SP $(0.75 \mu \mathrm{m})$ increases the burst frequency of the VRG in medullary slices of $\mathrm{PO}$ wild-type (top) and Chx10::DTA mice (bottom). The gray box marks the period between 60 and $180 \mathrm{~s}$ after SP application. $\boldsymbol{i}, \boldsymbol{k}$, The effects of exogenous SP on frequency $(i)$ and coefficient of variation of the interburst interval $(\boldsymbol{k})$ in medullary slices from wild-type (white bars; $n=5$ ) and Chx10::DTA (black bars; $n=5$ ) mice before SP application (control), between 60 and 180 s of SP (gray box), and between 180 and 500 s of $S P . j, l$, The effects of exogenous NMDA on frequency $(j)$ and coefficient of variation of the interburst interval $(\boldsymbol{I})$ in medullary slices from wild-type (white bars; $n=4$ ) and Chx10::DTA (black bars; $n=4$ ) mice before NMDA application (control), between 60 and 180 s of NMDA (gray box), and between 180 and $500 \mathrm{~s}$ of NMDA. Error bars indicate SEM. Scale bars: $\boldsymbol{d}, 20 \mu \mathrm{m} ; \boldsymbol{e}-\boldsymbol{g}, 100 \mu \mathrm{m}$.

Figure 4. Glutamatergic V2a neurons expressing Chx10 are found in the mRF of the medulla. $\boldsymbol{a}$, Schematic outline of a corona hemisection through the medulla of an adult mouse brain. Structures containing respiratory related neurons are shown: hypo- 

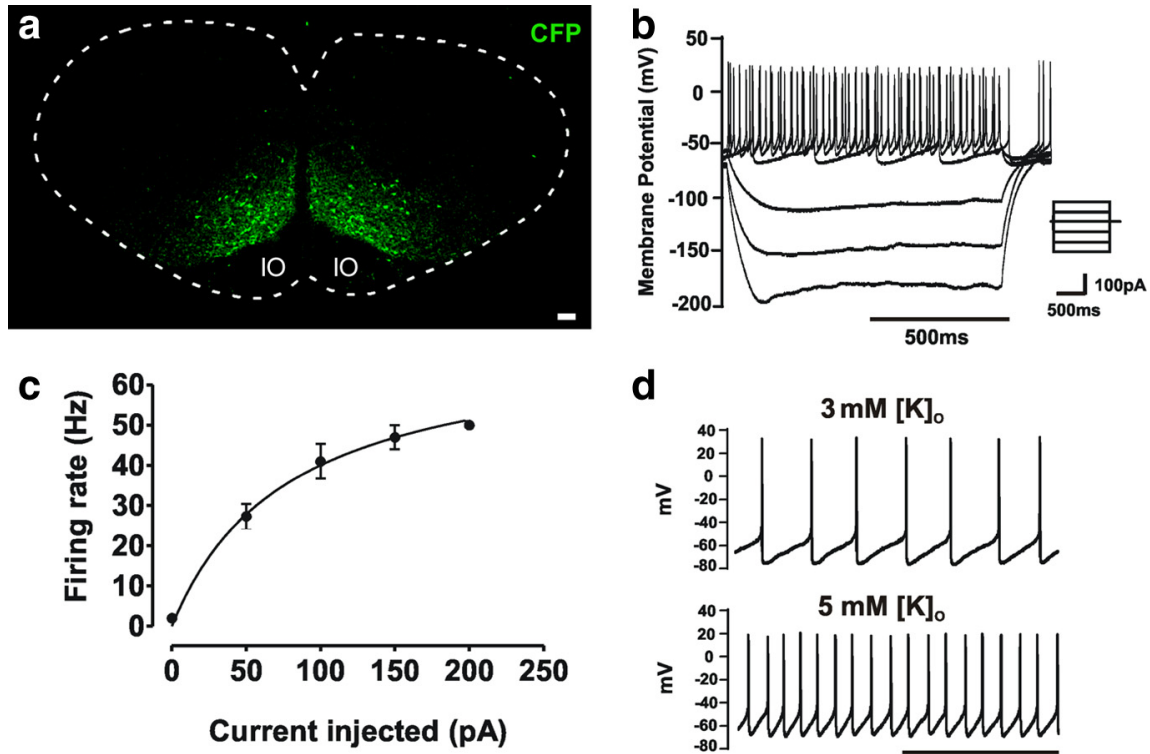

d

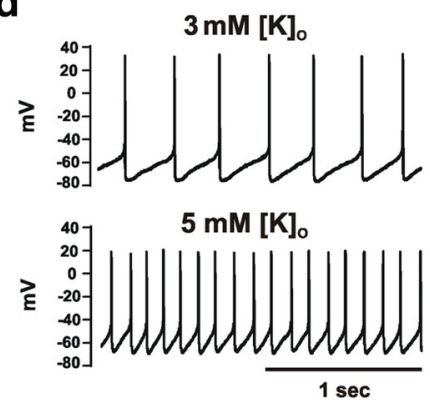

Figure 5. Firing properties of fluorescently labeled V2a neurons. $\boldsymbol{a}$, Coronal section from a PO Chx10::CFP mouse at the level of the pre-BötC. The soma of CFP-labeled V2a neurons are restricted to the mRF. $\boldsymbol{b}$ - $\boldsymbol{d}$, Whole-cell current-clamp recordings of CFP expressing V2a neurons in medullary slices made from neonatal Chx10::CFP mice. $\boldsymbol{b}$, V2a neurons exhibit a strong inward rectification $\left(I_{\mathrm{h}}\right)$ when hyperpolarized below $-150 \mathrm{mV}$. The inset shows current step protocol used to inject $50 \mathrm{pA}$ steps from -150 to $+100 \mathrm{pA}$. c, Relationship between current injection and mean firing rate in V2a neurons ( $n=4$ cells). Depolarization block was observed above a maximum firing frequency of $50 \mathrm{~Hz}$. Error bars indicate SEM. $\boldsymbol{d}$, Spontaneous tonic firing activity of a V2a neuron at a resting membrane potential of $-62 \mathrm{mV}$. Raising the extracellular $[\mathrm{K}]_{0}$ from 3 to $5 \mathrm{~mm}$ causes an increase in firing frequency but the firing pattern remains tonic. Scale bar, $100 \mu \mathrm{m}$.

GATA3 map to multiple locations including the raphe, $\mathrm{mRF}$, and more dorsal-lateral areas of the medulla (Fig. 4c). Next, we combined in situ hybridization and immunohistochemistry to test whether V2a neurons in the medulla, like the majority of V2a neurons in the spinal cord, express vglut 2 mRNA (Al-Mosawie et al., 2007; Lundfald et al., 2007; Crone et al., 2008). This analysis revealed that Chx10-expressing neurons in the $\mathrm{mRF}$ express mRNA for vglut2 (Fig. $4 d$ ). In Chx10::DTA mice, ablation of V2a neurons reduces $v g l u t 2$ expression in the $\mathrm{mRF}$ (Fig. $4 e, f$ ). Thus, in the medulla of P0 mouse, V2a neurons are located exclusively within the medial reticular formation and most of these neurons express vglut2.

Given that most medullary V2a neurons are glutamatergic, we asked whether the main deficiency in Chx10::DTA mice is the lack of excitatory drive. We sought to rescue the regularity and frequency of inspiratory burst activity in slices by providing an alternate source of excitation. Substance P (SP) is an endogenous excitatory chemical and the expression of SP in medulla is comparable in wild-type and Chx10::DTA mice (Fig. $4 g$ ). We added SP to the bath of medullary slices from P0 wild-type or Chx10::DTA mice and recorded VRG burst activity. As expected, SP increased the burst frequency in wild-type slices without affecting the regularity of the interburst interval (Fig. $4 h, i ; n=5$ wild-type, 5 Chx10::DTA). Bath application of SP also increased the frequency of bursting in slices from Chx10::DTA mice to levels similar to wild type (Fig. $4 h, i$ ). Moreover, the regularity of the interburst interval was restored in Chx10::DTA slices by treatment with SP (Fig. 4k). Similarly, bath application of NMDA also rescued the frequency and regularity of the respiratory rhythm in slices from Chx10::DTA mice to levels comparable with those observed in the slices from wild-type mice (Fig. $4 j, l ; n=4$ wild type, 4 Chx10::DTA). Rescue of the irregular respiratory rhythm in Chx10::DTA slices to near wild-type levels by the application of
SP and NMDA is consistent with the idea that the development of the basic respiratory network is not affected by targeted ablation of $\mathrm{V} 2 \mathrm{a}$ neurons. Instead, the loss of V2a neurons simply removes an excitatory input that is required to generate a regular respiratory motor rhythm.

\section{V2a neurons in the mRF show a tonic firing pattern}

To directly visualize the V2a neurons, we used Chx10::CFP mice in which these neurons express CFP (Crone et al., 2008) (Fig. 5a). Consistent with the immunohistochemical data, in the medulla of $\mathrm{P0}$ Chx10::CFP mice, CFP expression is restricted to the $\mathrm{mRF}$ in neurons that coexpress Chx10. We find that $98.4 \pm 0.2 \%$ of neurons expressing Chx10 in P0 medulla also express CFP, while CFP expression is not seen in neurons that do not express Chx10 $(n=4)$. We used Chx10::CFP mice to record from V2a neurons in the medullary slice preparation. Optical recordings of the firing pattern in medullary slices have revealed that neurons in the $\mathrm{mRF}$ do not show the characteristic burst firing pattern as observed within the preBötC (Koizumi et al., 2008; Mellen and Mishra, 2010). Consistent with these earlier reports, whole-cell patch-clamp recordings from V2a neurons in medullary slices obtained from $\mathrm{P} 0 \mathrm{Chx} 10$ ::CFP mice show that V2a neurons are spontaneously active and exhibit slow tonic firing with a mean frequency of $5.1 \pm 0.7 \mathrm{~Hz}$ and baseline membrane potential of $-58 \pm 2 \mathrm{mV}(n=8)$. Interspike intervals (mean, $208 \pm 32 \mathrm{~ms} ; n=5$ ) exhibited high regularity (coefficient of variation, $0.18 \pm 0.03$ ) within individual cells. A series of depolarizing current pulses (from 50 to $300 \mathrm{pA}$ ) increased the firing frequency up to a maximum of $50 \mathrm{~Hz}$, after which further current injection caused depolarization block (Fig. $5 c$ ). Spike frequency adaptation was not observed in any V2a neuron $(n=8)$. The presence of a hyperpolarization-activated cation current $\left(I_{\mathrm{h}}\right)$ was tested in current clamp by a series of DC current pulses (from -50 to $-150 \mathrm{pA}$ ). V2a neurons exhibited a rebound depolarization sag of $13.4 \pm 0.7 \mathrm{mV}(n=7)$ measured from a maximum hyperpolarization at $-120 \mathrm{mV}$ (Fig. $5 b$ ). Since many neurons in the medulla show burst firing at higher $[\mathrm{K}]_{\mathrm{o}}$, we increased the potassium concentration. Raising $[\mathrm{K}]_{\mathrm{o}}$ from 3 to $5 \mathrm{~mm}$ depolarized $\mathrm{V} 2 \mathrm{a}$ neurons and increased tonic firing frequency to $9.2 \pm$ $1.7 \mathrm{mV}(n=5$; Fig. $5 d)$. High potassium shortened the interspike intervals (mean, $141 \pm 36 \mathrm{~ms} ; n=5 ; p=0.027$ ) but did not significantly alter the ISI regularity $(\mathrm{CV}=0.18 \pm 0.03$ at $3 \mathrm{mM}$ and $0.15 \pm 0.03$ at $\left.5 \mathrm{~mm}[\mathrm{~K}]_{o} ; p>0.05\right)$ nor did it induce burst firing of $\mathrm{V} 2 \mathrm{a}$ neurons. These data demonstrate that the glutamatergic V2a neurons in the mRF of the mouse medulla likely generate a tonic excitatory drive.

\section{V2a neurons make excitatory contacts on neurons in the pre-BötC}

How might glutamatergic neurons in the mRF regulate burstfiring activity in the pre-BötC? We asked whether V2a neurons make direct contacts with neurons in the pre-BötC. In the medulla of neonatal Chx10::CFP mice, V2a neuron cell bodies are 
restricted to the $\mathrm{mRF}$, whereas CFPlabeled processes are observed both within the mRF and in the adjacent ventrolateral medulla. To localize the preBötC, we colabeled medullary tissue sections with anti-NK $\mathrm{N}_{1} \mathrm{R}$ and anti-ChAT. In the ventral lateral medulla, $\mathrm{NK}_{1} \mathrm{R}$ is expressed by neurons located in the NA (Fig. $6 a, b)$ and the pre-BötC. These two structures can be readily distinguished by the selective expression of ChAT in NA neurons (Fig. 6a,c). Adjacent tissue sections were labeled with anti-CFP and anti$\mathrm{NK}_{1} \mathrm{R}$ antibodies (Fig. 6d-f). In all neonatal Chx10::CFP mice analyzed $(n=5)$, CFP-labeled processes were found among $\mathrm{NK}_{1} \mathrm{R}$-expressing neurons that were located within the ChAT-negative pre-BötC. These data indicate that V2a neurons extend projections to the pre-BötC.

In Chx10::CFP mice, CFP-labeled V2a neurons are located throughout the brainstem and spinal cord. To determine the location of the $\mathrm{V} 2$ a neurons that project to the pre-BötC, we performed retrograde labeling. We identified the pre-BötC by its rhythmic firing pattern recorded in a transverse slice preparation (Smith et al., 1991; Ramirez and Richter, 1996). Upon identification of the pre-BötC, we injected fluorescein-dextran, a retrograde tracer (Fig. 7a). In three of four slice preparations, the fluorescein-dextran retrogradely labeled neurons. In these three cases, retrogradely labeled neurons were found within the mRF and many of these neurons expressed Chx10, indicating that these were V2a neurons (Fig. 7b). In these experiments, many Chx10 cells in the mRF were not labeled retrogradely, likely due to the small volumes of the tracer dye injected into the pre-BötC. However, we cannot rule out that some V2a neurons in the mRF might not project to the pre-BötC. Based on the anterograde CFP label and retrograde labeling, these data show that one target of $\mathrm{V} 2 \mathrm{a}$ neurons in the $\mathrm{mRF}$ is the pre-BötC.

We asked whether axon terminals from V2a neurons in the $\mathrm{mRF}$ establish glutamatergic synaptic contacts on neurons in the pre-BötC. In P0 Chx10::CFP mice, we identified CFP-labeled synaptic contacts by colabeling for vGLUT2, a vesicular transporter that localizes to presynaptic glutamatergic terminals. Tissue sections were triple labeled using anti-CFP, anti-vGLUT2, and anti-NK $\mathrm{N}_{1} \mathrm{R}$ antibodies and analyzed by confocal microscopy. This analysis revealed puncta that coexpressed CFP and vGLUT2 and are found in close proximity to $\mathrm{NK}_{1} \mathrm{R}$-expressing neurons in the pre-BötC (Fig. $7 c-l$ ). Consistent with previous reports that pre-BötC neurons make robust reciprocal glutamatergic contacts with each other (Funk et al., 1993), the vGLUT2 ${ }^{+} / \mathrm{CFP}^{+}$puncta comprise only a subset of all vGLUT2 ${ }^{+}$puncta within the preBötC (Fig. $7 g, l$ ). These data demonstrate that the glutamatergic input to pre-BötC neurons has multiple origins and includes contacts made by V2a neurons located in the mRF.

\section{Discussion}

In human infants, congenital central hypoventilation syndrome and sudden infant death syndrome present with slow, irregular
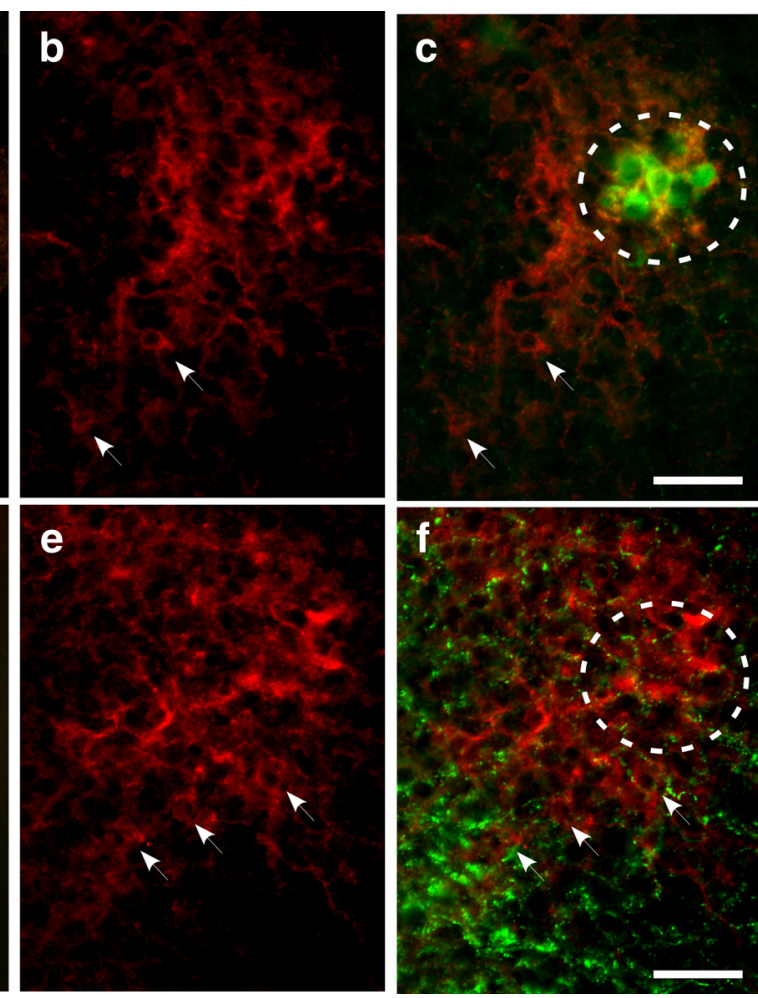

Figure 6. V2a neurons project to the pre-BötC. $\boldsymbol{a}-\boldsymbol{c}$, Coronal sections of the medulla from a PO Chx10::CFP mouse stained with R. The arrows mark some of the $\mathrm{NK}_{1} \mathrm{R}^{+}$neurons below the NA in the pre-BötC. CFP ${ }^{+}$fibers from V2a neurons project to the .

breathing. These syndromes underscore a special need to understand neural control of breathing in neonates. In this study, we demonstrate that, in both C57BL/6 and ICR strains of mice, targeted ablation of $\mathrm{V} 2 \mathrm{a}$ neurons decreases the frequency and regularity of breathing in the newborn. We trace the decreased frequency and loss of regularity in the breathing down to a minimal respiratory network contained within the well established medullary slice preparation. We also find that the frequency of the respiratory rhythm generated by this minimal respiratory network isolated from mice lacking the V2a neurons can be restored by the application of excitatory neurochemicals NMDA and Substance P. These findings indicate that breathing abnormalities observed in Chx10::DTA mice likely result from insufficient excitatory drive to the medullary respiratory network, and identify medullary V2a neurons as a critical component of the neural network that controls breathing in neonates.

\section{V2a neurons and neural control of breathing in neonates}

In both C57BL/6 and ICR strains of mice, targeted ablation of V2a neurons decreases the frequency and regularity of breathing in the newborn. However, in the absence of V2a neurons, the ability of newborn mice to survive past day 3 is dependent on the strain. All Chx10::DTA mice born to C57BL/6 dams die, while $40 \%$ of Chx10::DTA pups born to ICR dams survive. This difference in survival may be because C57BL/ 6 mice are more prone to breathing irregularities and apneas compared with other mouse strains (Stettner et al., 2008; Yamauchi et al., 2008) and therefore are more likely to succumb to further breathing irregularities caused by the loss of V2a neurons than ICR mice. It is also pos- 

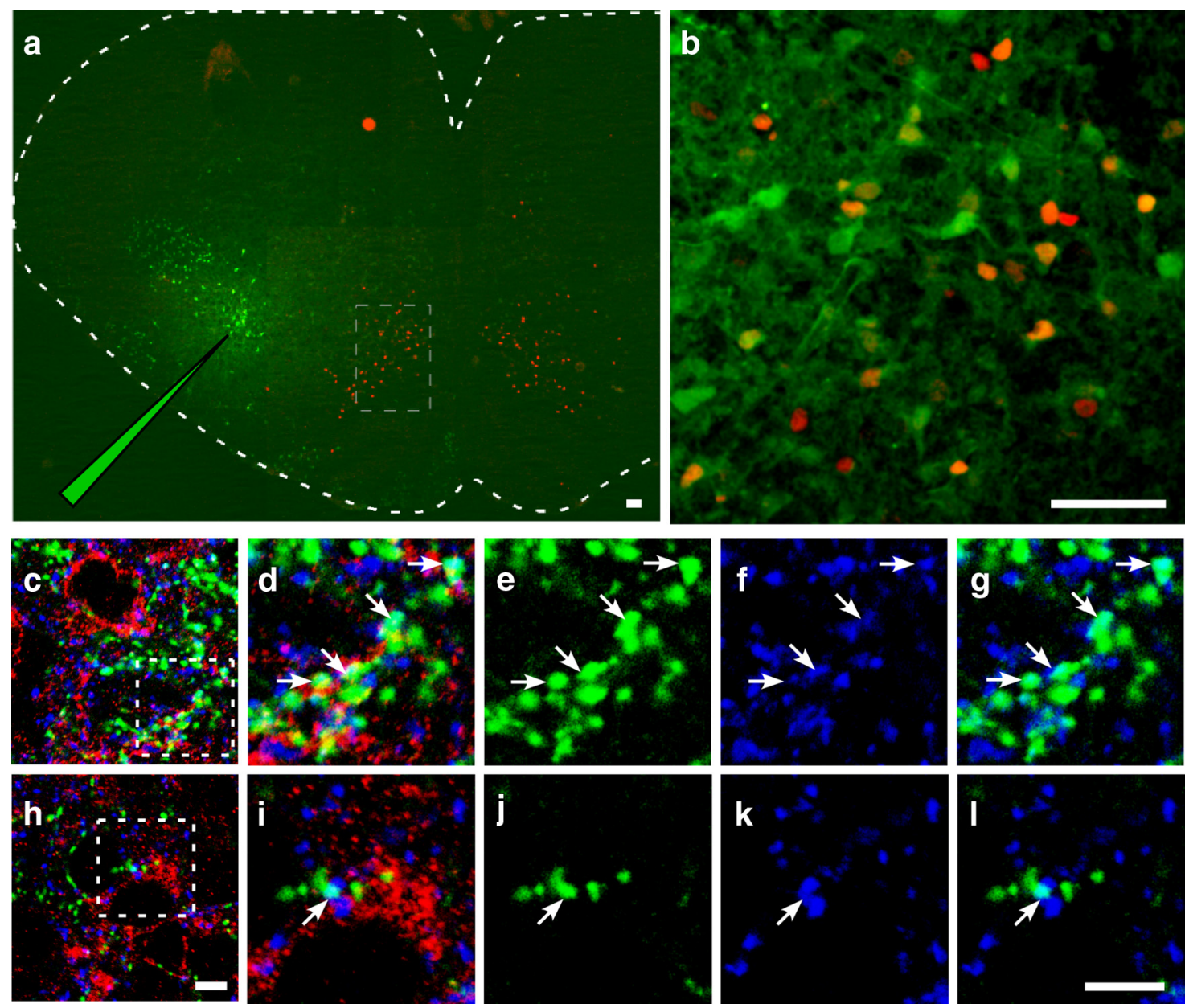

Figure 7. V2a neurons make vGLUT2-enriched synapses in the pre-BötC. $\boldsymbol{a}, \boldsymbol{b}$, Retrograde labeling of V2a neurons projecting to the VRG. The VRG was identified using electrophysiology based on rhythmic burst activity in medullary slices, and fluorescein-dextran (green) was injected to retrogradely label neurons projecting to this region. The green pipette drawing marks the site of injection in a cryostat section from the physiological slice preparation $(\boldsymbol{a})$. V2a neurons were identified using antibodies to Chx10 (red). The area of the mRF marked by a rectangle is shown at higher magnification in $\boldsymbol{b}$. Many neurons in the mRF can be retrogradely labeled (green) from the pre-BötC, including Chx10 neurons (yellow). Some Chx10 neurons are not retrogradely labeled (red). $\boldsymbol{c}-\boldsymbol{h}$, Confocal images of the pre-BötC from PO Chx10::CFP mice showing excitatory projections from V2a neurons onto the processes $(\boldsymbol{c}-\boldsymbol{g})$ and cell bodies $(\boldsymbol{h}-\boldsymbol{l})$ of $\mathrm{NK}_{1} R^{+}$neurons. NK $_{1} R$ immunoreactivity (red) marks the cell bodies and processes of specific neurons in the pre-BötC. vGLUT2 (blue) marks excitatory synaptic terminals and CFP (green) marks the processes of V2a neurons. The boxed areas $(\boldsymbol{c}, \boldsymbol{h})$ are shown at higher magnification in $\boldsymbol{d}-\boldsymbol{g}$ and $\boldsymbol{i}-\boldsymbol{I}$. Excitatory terminals from V2a neurons are indicated in white as overlap between green and blue $(\boldsymbol{g}, \boldsymbol{I})$. The arrows in higher magnification images indicate V2a excitatory terminals that are in contact with NK ${ }_{1} R$ processes $(\boldsymbol{d}-\boldsymbol{g})$ or cell body $(\boldsymbol{i}-\boldsymbol{I})$. Scale bars: $\boldsymbol{a}, \boldsymbol{b}, 50 \mu \mathrm{m} ; \boldsymbol{c}-\boldsymbol{l}, 5 \mu \mathrm{m}$.

sible that the functions of V2a neurons are not limited to motor behaviors such as breathing and locomotion and might include other repetitive behaviors such as suckling, chewing, or swallowing. Also, C57BL/6 dams are known to have poor motherly instincts and might fail to rear pups with deficiencies in any of these behaviors.

In contrast to gene knock-outs that affect neural progenitors or rhombomere identity, V2a neurons are ablated in Chx10::DTA mice only after these cells differentiate. Another advantage of using genetic ablation versus gene knock-out is the possibility of neurons acquiring new functions in knock-out studies. However, neural plasticity following embryonic manipulations is a well documented phenomenon and a compounding factor in all studies targeting genes or neurons in embryos. Three sets of data bolster our conclusion that the loss of V2a neuron function rather than plastic changes following their ablation in the embryo results in breathing abnormalities. First, surviving Chx10::DTA pups show marked improvement in respiratory frequency and regularity after postnatal day 4. This time period coincides with a dramatic decrease in endogenous opiates in the brainstem that normally occurs after the neonatal period in both mice and humans (Jansen and Chernick, 1983). A small proportion of Chx10::DTA C57BL/6 pups (10 of 159 pups) treated with naloxone (an inhibitor of endogenous opiates) once per day for at least 2 postnatal days survive past the weaning age (Crone et al., 2009). Because opiates depress the activity of pre-BötC neurons (Gray et al., 1999), inhibition of endogenous opiates likely compensates for the loss of excitation provided by V2a neurons. This observation indicates that the role of V2a neurons is to act as an excitatory counterbalance to endogenous inhibitors of breathing in neonates. Second, consistent with selective ablation of V2a neurons, extensive analysis of the expression of various factors expressed in the medulla shows no significant difference between Chx10::DTA and wild-type mice. These factors include the following: $\mathrm{NK}_{1} \mathrm{R}$, a marker expressed by many neurons in the preBötC; AChE, a marker for cholinergic motor and interneurons; serotonin, a marker for neurons in the raphe; SP, a marker for afferents to $\mathrm{NK}_{1} \mathrm{R}$-expressing neurons in the pre-BötC; GATA3, a transcription factor expressed by neurons in the raphe and also by inhibitory V2b neurons in the mRF; Evx1, expressed by V0 neurons of the medulla; and GAD67, a marker for inhibitory GABAergic neurons (S. Crone and K. Sharma, unpublished 
data). Furthermore, pre-BötC development based on the expression of $\mathrm{NK}_{1} \mathrm{R}$ follows the same time schedule in Chx10::DTA mice as in the wild-type. Third, in respiratory slice preparations, augmenting excitation by bath application of NMDA or SP compensates for the loss of $\mathrm{V} 2 \mathrm{a}$ neurons and restores regular burst firing by the pre-BötC, demonstrating that the main deficit in Chx10::DTA mice is reduced excitatory input to pre-BötC neurons. These data show that breathing abnormalities observed in neonatal Chx10::DTA mice are most likely due to the absence of V2a neuron function rather than a developmental defect produced by neural plasticity.

\section{V2a neurons and respiratory rhythm generation}

Glutamatergic transmission plays an important role in respiration (Funk et al., 1993; Rekling and Feldman, 1998). Inhibition of glutamatergic transmission using CNQX slows the breathing rhythm in a dose-dependent manner (Greer et al., 1991; Funk et al., 1993). Mice with a loss-of-function mutation in the NMDA receptor $\mathrm{NR}_{1}$ are able to generate normal respiratory rhythm (Funk et al., 1997) but show depressed breathing at birth (Poon et al., 2000). Mice lacking all vGLUT2-dependent glutamatergic transmission fail to produce a respiratory rhythm (WallénMackenzie et al., 2006). Neurons in the pFRG/RTN express vglut2, and developmental defects in the pFRG/RTN observed in Phox $2 b$ mutant and Math 1 null mice depress breathing (Dubreuil et al., 2008; Rose et al., 2009a). Thus, subtypes of glutamatergic neurons are likely to play distinct roles in the neural control of breathing.

In Chx10::DTA mice, only a subset of vglut2-expressing neurons is ablated. Based on the distribution of V2a neurons in the medulla, only the most medial and ventrally located vglut2expressing neurons are missing in respiratory slice preparations from Chx10::DTA mice. Recordings of pre-BötC burst firing activity in Chx10::DTA medullary slices show that V2a neurons located within the medullary slice are essential for maintaining a robust respiratory rhythm. V2a neurons are also located outside the medullary mRF. For example, in the rostral pontine tegmentum, the V2a neurons are located in the pedunculopontine and laterodorsal tegmental nuclei and within the pontine reticular formation (C. Hollands and K. Sharma, unpublished data). However, V2a neurons in the pedunculopontine nucleus are glutamatergic and distinct from the cholinergic neurons of the reticular activating system (Chamberlin and Saper, 1994; Kubin and Fenik, 2004; Rose et al., 2009a). Moreover, Cre-LoxP regulated selective labeling of these pontine $\mathrm{V} 2 \mathrm{a}$ neurons has revealed that they do not project to the VRC (C. Hollands and K. Sharma, unpublished data). Thus, V2a neurons residing within the medulla likely provide excitatory input to the pre-BötC; however, we cannot rule out potential roles for pontine V2a neurons in breathing.

\section{V2a neurons and the known respiratory networks}

The manner in which breathing is perturbed in mice lacking V2a neurons provides information about the role of tonic excitation in the neural control of respiratory rhythm. Approximate entropy measurements of the interburst interval in slices and Poincare maps of the breathing period demonstrate that the frequency of breathing varies unpredictably following the loss of V2a neurons. From this analysis, it is clear that following the loss of V2a neurons, mice do not simply skip breaths, as is the case when breathing is slowed by experimental opioid treatment in rats (Mellen et al., 2003). It is also important to note that the presence of tonic excitatory drive is a critical component of most compu- tational models of respiratory rhythm generation (Ogilvie et al., 1992; Butera et al., 1999a; Joseph and Butera, 2005; Purvis et al., 2007; Rubin et al., 2009). How might excitatory input from V2a neurons control frequency and stability of respiratory rhythm generation? One way that V2a neurons may promote rhythm generation is by altering the activity of pre-BötC neurons with intrinsic bursting properties, called "pacemaker neurons." By depolarizing neurons with pacemaker properties, V2a neurons may increase their frequency of bursting and thereby increase respiratory frequency (Butera et al., 1999a,b). A second possibility is that V2a neurons may influence "conditional pacemaker neurons." These neurons do not burst rhythmically when isolated from synaptic input, but have the potential to burst when neuromodulators alter their excitability (Rekling and Feldman, 1998; Viemari and Ramirez, 2006). Thus, V2a neurons might affect the rate and stability of the respiratory rhythm by controlling the state (quiescent, oscillatory, or bursting) of neurons in the respiratory circuit. Third, V2a neurons may control the timing of inspiratory bursts. By altering the excitability of pre-BötC neurons, V2a neurons may control the time to reach threshold for spiking and thus determine when inspiratory bursts are initiated. A recent model proposes that the respiratory rhythm is an emergent network property (Feldman and Del Negro, 2006). This network appears to include two rhythm generators, one for inspiratory rhythm and other for the expiratory rhythm. The tonic excitatory drive provided by V2a interneurons to either pacemaker or nonpacemaker neurons in the putative inspiratory rhythm generator, namely, the pre-BötC, is expected to increase frequency and regularity of the respiratory rhythm.

The experimental approach used in this study is based on an emerging concept that neurons derived from a distinct progenitor pool that expresses unique molecular markers often perform equivalent functions. This approach has been validated by numerous studies of motor circuits in the spinal cord that regulate locomotion (Stepien and Arber, 2008; Grossmann et al., 2010). For example, V2a neurons in the spinal cord make vGLUT2enriched synaptic contacts with commissural neurons and are required for stabilizing the locomotor rhythm as well as for maintaining left-right alternation (Crone et al., 2008, 2009). One type of commissural neuron that receives glutamatergic input from V2a neurons is the V0 class of interneurons. An intriguing parallel with the current findings is that V0 neurons in the spinal cord and $\mathrm{NK}_{1} \mathrm{R}$ neurons in the pre-BötC are derived from neural progenitors that express $d b x 1$ (Bouvier et al., 2010; Gray et al., 2010). In respiratory circuits, V2a neurons do not appear to be required for coordination between the left and right pre-BötC, as we observed simultaneous bursts in left and right pre-BötC in slice preparations from both wild-type and Chx10::DTA mice (data not shown). This difference between locomotor and respiratory circuits might be due to the inhibitory (V0 in the spinal cord) versus excitatory $\left(\mathrm{NK}_{1} \mathrm{R}\right.$ in the medulla) nature of the target neurons.

In conclusion, V2a neurons in the medulla provide a critical excitatory drive that promotes regular burst firing and a normal breathing pattern. This function of V2a neurons in the mRF has striking similarity to the role of V2a neurons in the lumbar spinal cord in stabilizing the locomotor rhythm.

\section{References}

Alheid GF, McCrimmon DR (2008) The chemical neuroanatomy of breathing. Respir Physiol Neurobiol 164:3-11.

Al-Mosawie A, Wilson JM, Brownstone RM (2007) Heterogeneity of V2derived interneurons in the adult mouse spinal cord. Eur J Neurosci 26:3003-3015. 
Amiel J, Dubreuil V, Ramanantsoa N, Fortin G, Gallego J, Brunet JF, Goridis C (2009) PHOX2B in respiratory control: lessons from congenital central hypoventilation syndrome and its mouse models. Respir Physiol Neurobiol 168:125-132.

Borday C, Chatonnet F, Thoby-Brisson M, Champagnat J, Fortin G (2005) Neural tube patterning by Krox20 and emergence of a respiratory control. Respir Physiol Neurobiol 149:63-72.

Bouvier J, Thoby-Brisson M, Renier N, Dubreuil V, Ericson J, Champagnat J, Pierani A, Chédotal A, Fortin G (2010) Hindbrain interneurons and axon guidance signaling critical for breathing. Nat Neurosci 13:1066-1074.

Butera RJ Jr, Rinzel J, Smith JC (1999a) Models of respiratory rhythm generation in the pre-Bötzinger complex. I. Bursting pacemaker neurons. J Neurophysiol 82:382-397.

Butera RJ Jr, Rinzel J, Smith JC (1999b) Models of respiratory rhythm generation in the pre-Bötzinger complex. II. Populations of coupled pacemaker neurons. J Neurophysiol 82:398-415.

Chamberlin NL, Saper CB (1994) Topographic organization of respiratory responses to glutamate microstimulation of the parabrachial nucleus in the rat. J Neurosci 14:6500-6510.

Chatonnet F, Wrobel LJ, Mézières V, Pasqualetti M, Ducret S, Taillebourg E, Charnay P, Rijli FM, Champagnat J (2007) Distinct roles of Hoxa2 and Krox20 in the development of rhythmic neural networks controlling inspiratory depth, respiratory frequency, and jaw opening. Neural Dev 2:19.

Cheng L, Arata A, Mizuguchi R, Qian Y, Karunaratne A, Gray PA, Arata S, Shirasawa S, Bouchard M, Luo P, Chen CL, Busslinger M, Goulding M, Onimaru H, Ma Q (2004) Tlx3 and Tlx1 are post-mitotic selector genes determining glutamatergic over GABAergic cell fates. Nat Neurosci 7:510-517.

Crone SA, Quinlan KA, Zagoraiou L, Droho S, Restrepo CE, Lundfald L, Endo T, Setlak J, Jessell TM, Kiehn O, Sharma K (2008) Genetic ablation of V2a ipsilateral interneurons disrupts left-right locomotor coordination in mammalian spinal cord. Neuron 60:70-83.

Crone SA, Zhong G, Harris-Warrick R, Sharma K (2009) In mice lacking v2a interneurons, gait depends on speed of locomotion. J Neurosci 29:7098-7109.

Del Negro CA, Morgado-Valle C, Feldman JL (2002) Respiratory rhythm: an emergent network property? Neuron 34:821-830.

del Toro ED, Borday V, Davenne M, Neun R, Rijli FM, Champagnat J (2001) Generation of a novel functional neuronal circuit in Hoxal mutant mice. J Neurosci 21:5637-5642.

Dubreuil V, Ramanantsoa N, Trochet D, Vaubourg V, Amiel J, Gallego J, Brunet JF, Goridis C (2008) A human mutation in Phox $2 b$ causes lack of $\mathrm{CO}_{2}$ chemosensitivity, fatal central apnea, and specific loss of parafacial neurons. Proc Natl Acad Sci U S A 105:1067-1072.

Duclos Y, Burnet H, Schmied A, Rossi-Durand C (2008) Approximate entropy of motoneuron firing patterns during a motor preparation task. J Neurosci Methods 172:231-235.

Feldman JL, Del Negro CA (2006) Looking for inspiration: new perspectives on respiratory rhythm. Nat Rev Neurosci 7:232-242.

Funk GD, Smith JC, Feldman JL (1993) Generation and transmission of respiratory oscillations in medullary slices: role of excitatory amino acids. J Neurophysiol 70:1497-1515.

Funk GD, Johnson SM, Smith JC, Dong XW, Lai J, Feldman JL (1997) Functional respiratory rhythm generating networks in neonatal mice lacking NMDAR1 gene. J Neurophysiol 78:1414-1420.

Gray PA, Rekling JC, Bocchiaro CM, Feldman JL (1999) Modulation of respiratory frequency by peptidergic input to rhythmogenic neurons in the preBötzinger complex. Science 286:1566-1568.

Gray PA, Janczewski WA, Mellen N, McCrimmon DR, Feldman JL (2001) Normal breathing requires preBötzinger complex neurokinin-1 receptorexpressing neurons. Nat Neurosci 4:927-930.

Gray PA, Hayes JA, Ling GY, Llona I, Tupal S, Picardo MC, Ross SE, Hirata T, Corbin JG, Eugenín J, Del Negro CA (2010) Developmental origin of preBötzinger complex respiratory neurons. J Neurosci 30:14883-14895.

Greer JJ, Smith JC, Feldman JL (1991) Role of excitatory amino acids in the generation and transmission of respiratory drive in neonatal rat. J Physiol 437:727-749.

Grossmann KS, Giraudin A, Britz O, Zhang J, Goulding M (2010) Genetic dissection of rhythmic motor networks in mice. Prog Brain Res 187:19-37.

Hinckley CA, Hartley R, Wu L, Todd A, Ziskind-Conhaim L (2005)
Locomotor-like rhythms in a genetically distinct cluster of interneurons in the mammalian spinal cord. J Neurophysiol 93:1439-1449.

Janczewski WA, Feldman JL (2006) Distinct rhythm generators for inspiration and expiration in the juvenile rat. J Physiol 570:407-420.

Jansen AH, Chernick V (1983) Development of respiratory control. Physiol Rev 63:437-483.

Joseph IM, Butera RJ (2005) A simple model of dynamic interactions between respiratory centers. Conf Proc IEEE Eng Med Biol Soc 6:5840-5842.

Koizumi H, Wilson CG, Wong S, Yamanishi T, Koshiya N, Smith JC (2008) Functional imaging, spatial reconstruction, and biophysical analysis of a respiratory motor circuit isolated in vitro. J Neurosci 28:2353-2365.

Kubin L, Fenik V (2004) Pontine cholinergic mechanisms and their impact on respiratory regulation. Respir Physiol Neurobiol 143:235-249.

Lieske SP, Thoby-Brisson M, Telgkamp P, Ramirez JM (2000) Reconfiguration of the neural network controlling multiple breathing patterns: eupnea, sighs and gasps. Nat Neurosci 3:600-607.

Lundfald L, Restrepo E, Butt SJ, Peng CY, Sharma K, Kiehn O (2006) Mammalian spinal V2a interneurons express Epha4 and are excitatory and ipsilaterally projecting. Soc Neurosci Abstr 32:252.9.

Lundfald L, Restrepo CE, Butt SJ, Peng CY, Droho S, Endo T, Zeilhofer HU, Sharma K, Kiehn O (2007) Phenotype of V2-derived interneurons and their relationship to the axon guidance molecule EphA4 in the developing mouse spinal cord. Eur J Neurosci 26:2989-3002.

Mellen NM, Mishra D (2010) Functional anatomical evidence for respiratory rhythmogenic function of endogenous bursters in rat medulla. J Neurosci 30:8383-8392.

Mellen NM, Janczewski WA, Bocchiaro CM, Feldman JL (2003) Opioidinduced quantal slowing reveals dual networks for respiratory rhythm generation. Neuron 37:821-826.

Ogilvie MD, Gottschalk A, Anders K, Richter DW, Pack AI (1992) A network model of respiratory rhythmogenesis. Am J Physiol 263:R962-R975.

Onimaru H, Homma I (2003) A novel functional neuron group for respiratory rhythm generation in the ventral medulla. J Neurosci 23:1478-1486.

Pagliardini S, Ren J, Gray PA, Vandunk C, Gross M, Goulding M, Greer JJ (2008) Central respiratory rhythmogenesis is abnormal in lbx1-deficient mice. J Neurosci 28:11030-11041.

Peng CY, Yajima H, Burns CE, Zon LI, Sisodia SS, Pfaff SL, Sharma K (2007) Notch and MAML signaling drives Scl-dependent interneuron diversity in the spinal cord. Neuron 53:813-827.

Pincus SM, Gladstone IM, Ehrenkranz RA (1991) A regularity statistic for medical data analysis. J Clin Monit 7:335-345.

Poon CS, Zhou Z, Champagnat J (2000) NMDA receptor activity in utero averts respiratory depression and anomalous long-term depression in newborn mice. J Neurosci 20:RC73(1-6).

Purvis LK, Smith JC, Koizumi H, Butera RJ (2007) Intrinsic bursters increase the robustness of rhythm generation in an excitatory network. J Neurophysiol 97:1515-1526.

Ramirez JM, Richter DW (1996) The neuronal mechanisms of respiratory rhythm generation. Curr Opin Neurobiol 6:817-825.

Rekling JC, Feldman JL (1998) PreBötzinger complex and pacemaker neurons: hypothesized site and kernel for respiratory rhythm generation. Annu Rev Physiol 60:385-405.

Rose MF, Ren J, Ahmad KA, Chao HT, Klisch TJ, Flora A, Greer JJ, Zoghbi HY (2009a) Math1 is essential for the development of hindbrain neurons critical for perinatal breathing. Neuron 64:341-354.

Rose MF, Ahmad KA, Thaller C, Zoghbi HY (2009b) Excitatory neurons of the proprioceptive, interoceptive, and arousal hindbrain networks share a developmental requirement for Math1. Proc Natl Acad Sci U S A 106:22462-22467.

Rubin JE, Shevtsova NA, Ermentrout GB, Smith JC, Rybak IA (2009) Multiple rhythmic states in a model of the respiratory central pattern generator. J Neurophysiol 101:2146-2165.

Schaeren-Wiemers N, Gerfin-Moser A (1993) A single protocol to detect transcripts of various types and expression levels in neural tissue and cultured cells: in situ hybridization using digoxigenin-labelled cRNA probes. Histochemistry 100:431-440.

Smith JC, Ellenberger HH, Ballanyi K, Richter DW, Feldman JL (1991) PreBötzinger complex: a brainstem region that may generate respiratory rhythm in mammals. Science 254:726-729.

Stepien AE, Arber S (2008) Probing the locomotor conundrum: descending the "V" interneuron ladder. Neuron 60:1-4. 
Stettner GM, Zanella S, Huppke P, Gärtner J, Hilaire G, Dutschmann M (2008) Spontaneous central apneas occur in the C57BL/6J mouse strain. Respir Physiol Neurobiol 160:21-27.

Thaler J, Harrison K, Sharma K, Lettieri K, Kehrl J, Pfaff SL (1999) Active suppression of interneuron programs within developing motor neurons revealed by analysis of homeodomain factor HB9. Neuron 23:675-687.

Thoby-Brisson M, Karlén M, Wu N, Charnay P, Champagnat J, Fortin G (2009) Genetic identification of an embryonic parafacial oscillator coupling to the preBötzinger complex. Nat Neurosci 12:1028-1035.

Viemari JC, Ramirez JM (2006) Norepinephrine differentially modulates different types of respiratory pacemaker and nonpacemaker neurons. J Neurophysiol 95:2070-2082.

Viemari JC, Bévengut M, Burnet H, Coulon P, Pequignot JM, Tiveron MC, Hilaire G (2004) Phox2a gene, A6 neurons, and noradrenaline are essential for development of normal respiratory rhythm in mice. J Neurosci 24:928-937.
Wallén-Mackenzie A, Gezelius H, Thoby-Brisson M, Nygård A, Enjin A, Fujiyama F, Fortin G, Kullander K (2006) Vesicular glutamate transporter 2 is required for central respiratory rhythm generation but not for locomotor central pattern generation. J Neurosci 26: 12294-12307.

Wilson JM, Hartley R, Maxwell DJ, Todd AJ, Lieberam I, Kaltschmidt JA, Yoshida Y, Jessell TM, Brownstone RM (2005) Conditional rhythmicity of ventral spinal interneurons defined by expression of the Hb9 homeodomain protein. J Neurosci 25:5710-5719.

Yamauchi M, Ocak H, Dostal J, Jacono FJ, Loparo KA, Strohl KP (2008) Post-sigh breathing behavior and spontaneous pauses in the C57BL/6 (B6) mouse. Respir Physiol Neurobiol 162:117-125.

Zhang Y, Narayan S, Geiman E, Lanuza GM, Velasquez T, Shanks B, Akay T, Dyck J, Pearson K, Gosgnach S, Fan CM, Goulding M (2008) V3 spinal neurons establish a robust and balanced locomotor rhythm during walking. Neuron 60:84-96. 